\title{
Space Habitat Design Integration Issues
}

\author{
Marc M. Cohen \\ Space Projects Division, NASA-Ames Research Center
}


The appearance of this ISSN code at the bottom of this page indicates SAE's consent that copies of the paper may be made for personal or internal use of specific clients. This consent is given on the condition, however, that the copier pay a $\$ 7.00$ per article copy fee through the Copyright Clearance Center, Inc. Operations Center, 222 Rosewood Drive, Danvers, MA 01923 for copying beyond that permitted by Sections 107 or 108 of the U.S. Copyright Law. This consent does not extend to other kinds of copying such as copying for general distribution, for advertising or promotional purposes, for creating new collective works, or for resale.

SAE routinely stocks printed papers for a period of three years following date of publication. Direct your orders to SAE Customer Sales and Satisfaction Department.

Quantity reprint rates can be obtained from the Customer Sales and Satisfaction Department.

To request permission to reprint a technical paper or permission to use copyrighted SAE publications in other works, contact the SAE Publications Group.

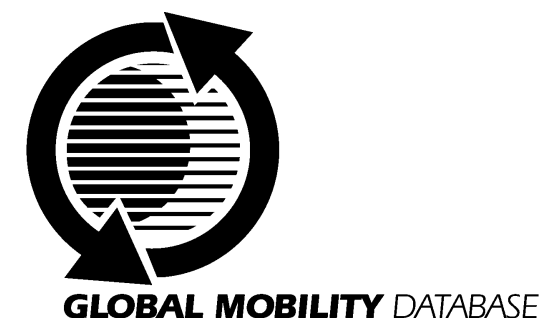

All SAE papers, standards, and selected books are abstracted and indexed in the Global Mobility Database

No part of this publication may be reproduced in any form, in an electronic retrieval system or otherwise, without the prior written permission of the publisher.

\section{ISSN 0148-7191}

Copyright 1998 Society of Automotive Engineers, Inc.

Positions and opinions advanced in this paper are those of the author(s) and not necessarily those of SAE. The author is solely responsible for the content of the paper. A process is available by which discussions will be printed with the paper if it is published in SAE Transactions. For permission to publish this paper in full or in part, contact the SAE Publications Group.

Persons wishing to submit papers to be considered for presentation or publication through SAE should send the manuscript or a 300 word abstract of a proposed manuscript to: Secretary, Engineering Meetings Board, SAE.

\section{Printed in USA}




\title{
Space Habitat Design Integration Issues
}

\author{
Marc M. Cohen \\ Space Projects Division, NASA-Ames Research Center
}

Copyright (c) 1998 Society of Automotive Engineers, Inc.

\begin{abstract}
This paper explores the issues of integrating all the elements necessary to support a healthy and productive crew in a space habitat. The problem of this system integration hinges largely upon the nature of the structural system, both of the primary pressure envelope and the internal secondary structure of floors, partitions, hard points and stand-offs. This habitat integration must accommodate the life support system, stowage, private quarters, group activity areas, and working areas. The working areas may include laboratories, control centers, maintenance and repair facilities. Human factors engineering design stands as a challenge throughout the habitat.
\end{abstract}

The distinction between an interplanetary habitat for zero gravity and a planetary surface habitat for a gravity field serves as an important design driver and discriminator. Environmental effects such as ionizing radiation, ultraviolet radiation, meteoroids, extremes of hot and cold act as determining factors as well. These requirements can be so demanding that they overshadow the specific objectives of particular human exploration missions. The means and methods of meeting these requirements raise the issue of what it means to build a lunar or planetary infrastructure for human habitation.

\section{INTRODUCTION}

The purpose of this paper is to explicate the planetary habitat construction issues with an emphasis upon how they affect habitat design integration. Many designers use the term "integration" merely to mean the avoidance of conflicts and interferences. However, the basis for this paper is to approach design integration as a pro-active, anticipatory strategy. This strategy begins from a systematic survey of space habitat construction materials, products, and techniques. This survey then provides the approach for planning design integration as a positive process for solving known problems, rather than as a reactive process one that seeks to mitigate or "work around" these problems.

The choice of construction methods and materials creates profound implications for the planetary habitat as design product. It is vital for space architects to under- stand these properties and consequences. The search for this understanding is the basis for the materials and products survey that comprises most of this essay.

Unlike many essays upon planetary architecture, this paper does not assume specific phase of maturity such as a "first Mars outpost" or "first Lunar outpost "mature lunar base" approach. Rather, it looks at the design integration issues that would apply to an interplanetary, planetary or lunar surface habitat at virtually any phase of maturity. It recognizes that there will be and must be a continuum of habitat configuration development. Cohen \& Kennedy (1997, p. 85) describe three such phases in lunar/Mars surface habitat development and maturation:

Class 1: Pre-integrated, Hard Shell Module

Class 2: Prefabricated, Surface Deployed

Class 3: ISRU Derived Structure with Integrated Earth Components

Figure 1 shows the Class 1 completely pre-integrated, hard shelled pressure vessel, as a landed surface habitat. Figure 2 shows the Class 2 prefabricated, surface deployed, assembled, or inflated habitat. Figure 3 shows a very preliminary concept for a Class 3 in situ constructed habitat of lunar or Martian concrete.

Although this paper begins from the baseline in the NASA Design Reference Mission for the Human Exploration of Mars (Hoffman \& Kaplan, 1997), it addresses the integration issues that affect all three classes of habitat development.

\section{CSI SIXTEEN DIVISION "MASTERFORMAT" INDEX}

This explication follows the Construction Specification Institute's (CSI) Sixteen Division format that encompasses all the products and materials for conventional construction. The applicability of this format suggests that construction on the Moon or Mars is not fundamentally different from construction on Earth. The difference derives from the unforgiving nature of the lunar and Martian environments toward any construction failure. The first several CSI divisions address materials: concrete, masonry, metals, and plastics, but the later ones address 
products and components. These are the CSI Sixteen divisions, slightly adjusted to the Space Habitat metier.

1. General Provisions

2. Site Planning and Site work

3. Concrete

4. Masonry

5. Metals

6. Plastic and Composites

7. Thermal and Moisture Protection

8. Doors and Windows

9. Finishes

10. Specialties

11. Equipment

12. Furnishings

13. Special Construction

14. Conveying Systems

15. Mechanical Systems

16. Electrical and Data Systems

The choice of both materials and components for lunar and planetary habitats demands careful consideration. Many of the traditional aerospace industry assumptions require scrutiny before making these selections. It is especially important to understand the system wide and design integration implications of these choices.

\section{GENERAL PROVISIONS: HABITAT DESIGN ASSUMPTIONS}

Several key assumptions shape the Habitat Design, including the crew health and fitness, single pressure atmosphere, redundancy for reliability and safety, multiple pressurized volumes, and the life-critical habitat core. Each of these assumptions suggests profound implications for habitat design integration (Cohen, 1996, AAS 95-491).

CREW HEALTH \& FITNESS - The crew will arrive in good physical and mental condition. They will be able to ambulate safely by EVA to the habitat immediately upon arrival on the surface.

GETTING THERE VERSUS BEING THERE - Clearly, the surface facility is distinct from the interplanetary transportation system. The Mars surface crew does not "fly the first habitat down to the surface," because that habitat is not primarily a propulsive vehicle. It is a payload on an automated, remote controlled lander. The Habitat should not conform to the severe Reliability requirements that characterized a propulsive vehicle.

MARS LANDER VERSUS HABITAT - Neither the Mars crew lander (MEV) nor the crew ascent vehicle is part of the Habitat Core. The Lander and Habitat Core may arrive on Mars during separate launch opportunities, without prejudice to the capabilities of either one.
SINGLE PRESSURE ATMOSPHERE - There will be a single atmospheric pressure that obviates the need for internal airlocks. This pressure regime will optimize for EVA operations, human health and for plant growth. It will be acceptable to vary the local gas mix within specific volumes so long as the overall pressure is uniform. For example, it may be acceptable to maintain a higher partial pressure of $\mathrm{CO} 2$ in the greenhouses to accelerate plant growth $\mathrm{OR}$ a higher partial pressure of $\mathrm{O} 2$ in the EVA airlock antechamber to enable a zero-prebreathe EVA and ensure against aerospace bends. However, the total pressure should be the same throughout the Habitat and FMO to assure safe and easy egress from one pressure volume to another.

REDUNDANCY - The key to reliability and safety in critical Habitat systems is to provide "like redundancy" of the same capability, "unlike redundancy" of multiple capabilities that perform the same function, or distribution of essential capabilities in multiple locations.

MULTIPLE VOLUMES - There will be at least two, separate, isolatable pressurized volumes within the Habitat core to allow egress from one volume to the other in contingency situations. These contingencies include fire, contamination, loss of pressure, or other event that compels the crew to evacuate one of the volumes. It will be possible for evacuating crew members to close the hatches between volumes quickly and easily.

THE HABITAT CORE - The Habitat provides all the basic Life-Critical habitation functions (safe haven), enhanced by the pressurized rover and inflatables capabilities. It also provides most of the Mission-Critical capabilities for both habitation and IVA science activities. Most of the Mission-Discretionary capabilities reside outside the Habitat core, in the inflatables (greenhouses \& rover garage) and in the pressurized rovers.

\section{SITE}

The major considerations for site selection include proximity to appropriate locations of scientific interest for exploration and to resources suitable for in-situ utilization (Cohen, 1996, AAS 95-491). These proximity requirements must balance with the characteristics of the ground and the ease of landing in the immediate vicinity.

LOCAL SITE FACTORS - LANDING ZONE - According to the Mars Design Reference Mission (Hoffman \& Kaplan, 1997) profile used in this study, as many as four landers of approximately 40 to 50 mTons each would fly to Mars on each launch opportunity of approximately 60 days, every 26 months. This flight pattern suggests short periods of relatively intensive use of the landing zone, followed by long periods of inactivity. The major installation at the landing zone that would always operate is the insitu resource utilization (ISRU) production plant for ascent vehicle fuel. Although the exact formulation of this fuel is open to discussion, the idea is to deliver the ascent 
vehicle "dry" to the Mars surface, and then to fill its tanks with fuel processed from the Mars atmosphere.

It is possible that each ascent vehicle will carry its own ISRU fuel plant. However, it may turn out more efficient to have a larger capacity permanently on the ground, consisting of one large plant or several smaller plants, making use of the empty tanks on used landing descent stages to store the propellant as they accumulate it. Having this "tank farm" filled and in place would make it possible to fuel an ascent vehicle soon after it landed, without having to wait months or years for it to process enough of its own fuel to take off again. This operational scenario implies that after every lander arrives at the landing zone, a traction engine will move it away from the primary landing area to a perimeter zone.

If the ISRU propellant plant requires an external source of power, it may be beneficial to set up solar photo-voltaic arrays or a nuclear power generator, connected by a cable to the ISRU plant. It would be necessary in both cases to protect the plants from dust and ejecta. It would be possible to install the reactor nearby in a deep crater. However, the only way to protect the photovoltaic arrays (which will be very sensitive to ejecta dust diminishing their capacity to generate power) will be to locate them at a substantially greater distance from the landing zone, with a longer cable.

HABITAT SITE SELECTION -- LOCAL FACTORS - The Habitat site must accommodate the Habitat core, the habitat support functions and all the activities that occur around them. The habitat core consists of a cluster of elements. Following the safety criteria (Cohen, 1996, AAS 95-491, pp. 490-499) generally there will be two of everything, and more than two in the case of certain Lifecritical components. Like the landing zone, the habitat system may employ a nuclear reactor or photo-voltaic arrays or both. The best location for the reactors again would be in a small crater to provide radiation shielding. Protecting the photo-voltaics from dust will not be as criti$\mathrm{cal}$ as at the landing zone that has the problem of ejecta.

Like the landing zone, it may be advantageous to locate a fuel production ISRU plant close to the power supplies, in this case to produce fuel for the pressurized roving vehicles. The combination of the ISRU plant and power reactor should be at least $1000 \mathrm{~m}$ from the habitat to protect it against possible mishap or explosion. The power generator provides electricity to the Habitat through a cable that may extend several hundred meters, all of which robots emplace. The design of the base must route this cable to avoid the rover and traction engine operation areas to protect it from being run over and damaged. It is probably not necessary to bury the cable in a trench IF it is possible to safely route it away from traffic. However, it would be beneficial to bury it under a small mound or berm of soil to protect it from ultraviolet radiation or accidental damage.

The site plan would place the Habitat cluster close to the base of a cliff or escarpment for increased radiation pro- tection (Simonson, 1996), but not so close as to be in danger of falling rock. The area immediately around the habitat core, to a radius of about $50 \mathrm{~m}$, should be clear of all obstacles with well-consolidated soil that can bear the loads that the habitat imposes without excessive or uneven settlement. It may be practical to use the traction engine to help compact loose soil before emplacing the habitats on it. If the Habitat modules weigh $40 \mathrm{mT}$ dry, they may weigh twice as much, with their water and atmosphere tanks filled, imposing perhaps $80 \mathrm{mT}$ each on the soil. This ground should be strong enough to support the Habitats without needing a foundation or any specialized site preparation beyond rolling with a traction engine.

\section{CONCRETE}

There have been many proposals to develop lunar or Martian concrete using in-situ resources. Concrete would be valuable to build foundations on which to emplace large, heavy habitats. There are also suggestions that concrete may fulfill a role in building "Class 3 " primary habitat structure that could hold an atmosphere (Cohen \& Kennedy, 1997).

The drawback of concrete is the need for water to hydrate the cement component. The great irony of concrete is that with water is so scarce on both Mars and the Moon - if concrete existed naturally -- the ISRU advocates would be campaigning to mine the concrete to extract the water. Use of conventional concrete would require substantial water resources. However, civil engineers have proposed several innovative substitutes for liquid water in the hydration process. Lin et al (1996) propose a dry mix, steam injection method. McKay and Carlton propose an alternative sulfer process (1996). It may be possible to use the water that Lunar Prospector found recently at the lunar South Pole, however, extracting and processing this water would require a large industrial plant, comparable to an ore reduction mill at a large mine on Earth. There would be the additional energy demand to melt and maintain the water in liquid form for use in hydrating the concrete. The costs and mass of equipment necessary for use of concrete is prohibitive at this time and for the foreseeable future.

\section{MASONRY}

Unlike concrete, masonry does not require a great deal of water to move, form, or emplace it, or to react its components. Masonry is the product of fire, and Nadar Khalili demonstrated the feasibility of firing an entire masonry structure in place, rather than firing bricks individually (Khalili, 1985, 1986, 1988, 1990). On the Moon or Mars, it may be possible for Khalili's vitrified in place masonry to hold atmospheric pressure. Vitrification in place would require an intense chemically generated fire in a temporary oxygen rich atmosphere. Bruce MacKenzie proposes to use masonry vaults, backing a pressure membrane, as primary structure to hold an atmosphere (MacKenzie, 1988, 1988, 1998). To create lunar or mar- 
tian masonry structure would require a digging and compacting capability to form the regolith into appropriately sized "bricks." Then a robotic system would assemble the bricks to form the structure. Other applications for masonry construction are to build foundations and to provide a radiation shielding envelope around Habitat modules. Like concrete, masonry would qualify as a "Class III" in situ structure under the Mars Habitats and Surface Construction Road Map (Cohen \& Kennedy, 1997).

\section{METALS}

Metals are appropriate for virtually every structural application on a planetary or interplanetary habitat. These applications include both "primary" pressure vessel structure and "secondary" interior structure. The primary structure is essential to contain the atmosphere and keep the crew alive. The secondary structure supports all the internal outfitting within the pressure vessel, and constitutes the single most important and wide-reaching integration system.

ALUMINUM PRESSURE VESSELS - Most serious proposals for planetary habitats invoke the aluminum pressure vessel as the standard primary structure. Designers understand Aluminum very well for building pressure vessels, and industry practice allows designers to rely upon excellent quality assurance in a quasi-sterile factory on Earth. Aluminum also offers a modicum of radiation protection, although it would need a significant supplement for long-term radiation shielding, both in interplanetary space and upon the planetary surface (Cohen, 1996, Cohen, 1997). Aluminum also plays a role in the many other structures necessary for a planetary base.

TITANIUM - Another preferred metal for "other structures" is titanium. However, titanium is not appropriate for habitat primary structure or interiors because it reacts readily with oxygen. Probably, interplanetary and planetary habitats will employ an atmosphere with lower pressure than one atmosphere, with a higher partial pressure of oxygen, making it incompatible with titanium. Titanium makes an excellent material for structures entirely outside the pressurized atmosphere, such as lander legs, trunnion fittings, ramps, stairs, ladders, etc.

INTERNAL SECONDARY STRUCTURES - Aluminum is appropriate for internal, secondary structure within the habitat. The design of this secondary structure is a key to making the habitat interior usable for accommodating all the furnishings and outfitting to support a human crew. The main precedents in this area are the Skylab "triangle grid" floors, and the interior "stand-off" and rack structures used on the International Space Station modules. Planetary and interplanetary habitats are likely to be larger diameter than either the Space Station at about $4.25 \mathrm{~m}$ or Skylab at $6.35 \mathrm{~m}$. Many proposals propose the diameter of planetary and interplanetary habitats at 7 to 10 meters. At these larger spans, the secondary structure must take on the characteristics of a robust framing system that is no longer directly dependent upon the primary pressure vessel structure to carry all loads directly on stand-offs, as on Space Station. It becomes necessary to design the connection between the interior, secondary structure and the primary pressure vessel structure to prevent local stress concentrations from occurring in the pressure vessel around the connection point. This stress concentration avoidance means that the secondary to primary structure connection probably must be hinged or pinned to avoid transfer of bending moment and shear loads. The secondary structure must handle these loads instead, entirely within its own span. In addition, the design should avoid conflict between the expansion and contraction of the pressure vessel and the relative stability of the internal secondary structure. Any of these conflicts can yield to stress fractures or localized fatigue.

CONNECTORS AND HARD POINTS - A system of attachment connectors and attachment hard points will be a vital part of the secondary structure. In its most conventional sense, the secondary structure provides floor and ceiling to support partitions and equipment. These connectors play the role of securing all these components against movement and vibration during launch, zero-gravity, and Mars atmospheric entry and landing. Typically, these connectors must resist at least 5 Gs.

UTILITY VOLUMES - The secondary structure also provides the space for the utility access and distribution system through a chaseway, plenum, or other dedicated volume. The design of these interstitial utility spaces is in many respects more difficult than the design of the crew's habitable environment. The clearances are often very tight, access to every part essential, and the ergonomics of crew access to these places can be very demanding. It is a cardinal error to regard utility chases or plenums as residual spaces in which to hide wiring and ductwork. Instead, the role of the utility system and its spatial envelope is so critical that it requires equal emphasis with the principal living quarters and work spaces.

\section{PLASTIC AND COMPOSITES}

The most often suggested substitutes for metals in primary structure are composites or inflatables. Both offer promises and limitations as a substitute for aluminum.

COMPOSITES - A composite hard structure offers many of the advantages of aluminum for a hard pressure vessel, with the added advantage of lighter weight. However, composites and inflatables tend to offer significantly less radiation shielding than aluminum, although some polymer-based composites offer promise as shielding. The best plastic for radiation shielding is polyethylene, which has limited structural properties. Hard composites may bring another complicating factor for human-rated pressure vessel. At the size required for planetary and interplanetary habitats, the most likely composite structures will be laminates. Laminates make excellent shields 
against micrometeoroid or debris impacts. However, the same property that makes them good shields raises a question about them for human-rated pressure vessels: they absorb impact energy by delaminating. It is difficult to inspect a composite structure non-destructively for this type of failure and even more difficult to repair it (Cohen, 1986, pp. 526-527). Aluminum is easy to inspect, even in the field, and easier to repair, even under field conditions. Another aspect of composites concerns the transmission of noise and vibration. In a contract for the Space Station program, Rimas Vaicaitis found that studies of both single and double wall shells "tend to indicate that more noise is transmitted at most frequencies by a shell made from composite materials" [compared to aluminum]. This noise transmission was approximately ten $\mathrm{dB}$ greater than aluminum at most of the spectral peaks from 100 to $800 \mathrm{~Hz}$ (Vaicaitis, 1985).

INFLATABLES - Offer the promise of radically lighter weight habitat structures. Multiple laminated inflatable envelopes with several layers of pressure membrane separated by plastic foam to afford a stand-off distance between the pressure membranes. Kriss Kennedy at Johnson Space Center has been testing such a multilaminate for a proposed $10 \mathrm{~m}$ diameter "TransHab" that could serve as an interplanetary habitat to take a crew to Mars. The TransHab takes the form of a giant tire mounted on a hub that contains all the secondary structure, which can deploy into the inflated volume. This ingenious solution belies the difficulty of outfitting and utilization of inflatable habitats -- how to connect secondary structure to an inflatable membrane. Figure 4 shows a cutaway view of the TransHab configuration, showing the tire-like inflatable membrane and its hard hub or core.

There may also be worthy applications for inflatable habitats on the Mars surface. Jenine Abarbanel of Colorado State University has proposed a system of semi-rectangular inflatable surface habitats. Abarbanel has demonstrated that the air pressure inside these habitats is more than ample to support substantial regolith mass deposited on the outside of the habitat to afford sufficient radiation shielding.

\section{THERMAL AND MOISTURE PROTECTION}

This CSI division traditionally deals with protecting the living environment from changes in the weather or climate outside. Although external moisture penetration is not a problem, the thermal protection issues are much more extreme.

THERMAL PROTECTION - On both the Moon and Mars, because of the lack of an atmosphere with significant heat capacity, the habitat will experience external temperature swings of hundred of degrees Celsius during the change from day to night. The primary means of protecting the habitat from these temperature swings is layering of thermal insulation and reflective foils. There are a variety of appropriate products, including kapton foils and the original "space blankets." It is important not to confuse the external thermal flux with internal thermal loads. In a space habitat, the major thermal task is to reject or reprocess waste heat from inside the habitat itself, which is the job of the life support system, covered here in Division 15.

MOISTURE PROTECTION - Another unique issue is that the major moisture protection challenge is not external but internal. The crew members perspire and respire water vapor all the time, and if the life support system does not control it, can condense on cold surfaces throughout the habitat. Another potential source of water is leaks from water systems, including water shields for radiation protection. Water can be highly corrosive to micro electronics, and can contribute to oxidation of a number of materials. Water sprinklers can be extremely useful for fire protection, and is non-toxic compared to halon gases, but then the problem is how to clean up and recapture or dispose of the water. This internal moisture protection remains largely unexplored.

\section{DOORS AND WINDOWS}

Doors and windows are as important in a space habitat as in a terrestrial home, and moreso in the sense that they help to contain and isolate the atmosphere within it. Doors and windows give a phenomenological meaning to the boundaries that walls create. By being to pass through these walls or see through them, people become aware of their extent and limitations. Doors and windows are essential to the experience of what is inside and what is outside, and the relation between the two domains.

DOORS - May play two principal roles: privacy or separation within the space habitat, and providing a sealable pressure port between habitat modules, or between the habitat and the cold vacuum of space. Non-pressure doors are the most similar to their terrestrial counterparts in homes, aircraft, submarines or ships -- supported by the secondary structure and integrated within the panelization or partition system. Pressure doors are vastly more complex and demanding both in terms of design and performance. The pressure port door must bear a load of at least one atmosphere, $10,690 \mathrm{~kg} / \mathrm{m} 2(14.7$ pounds/in2). Resisting this load, and the interruption in the primary pressure vessel requires massive structure around the pressure port, with a robust system of seals. Pressure ports between pressurized modules must also carry utility connectors for ventilation, life support, other gases and fluids, power and data communications. The Space Shuttle port from the middeck to the SpaceHab or Spacelab in the payload bay is a $1 \mathrm{~m}$ (40") "D" shaped hatch. The Space Station port is a $1.25 \mathrm{~m}$ (50") square hatch with $.25 \mathrm{~m}$ radiused corners. The design of the pressure port embodies many functional and operational considerations that will influence the character of the connection between habitable modules. 
AIRLOCKS - Comprise a special class of doors, analogous to a weather-tight vestibule that separates the weather outside from the inside. In a Space habitat, the separation occurs between two completely different atmospheres, as on Mars, or between the cabin atmosphere and the vacuum of space. There is a vast complex of deaign issues associated with airlock design, beginning with the type of space suit that isupport. These considerations encompass airlock volume, power consumption, pumpdown rate, compression ratio, thermal cooling of the pump, and the airlock to suit interface, including suit servicing and regeneration of portable life support. Vital performance measures include preservation of atmosphere, speed and ease of cycling through the airlock and accommodation of the buddy team. On the planetary surface, the special consideration of dust control arises. (Cohen, 1987; Cohen, 1995).

WINDOWS - Provide two functions: the ability to observe specific things outside the habitat and the habitability enhancement of being able to look out of the confined environment of the habitat, thereby achieving a larger sense of space. Windows to the outside must withstand the pressure differential. Pressure windows typically are laminates or assemblies of multiple layers or transparent materials. On the exterior surface, a planetary habitat window needs protection from dust, impact, and abrasion. One caveat is that the lexan, polycarbonate, or plexiglas type plastics -- commonly favored for such protective applications -- tend to be vulnerable to chemical attack and crazing from contact with certain high energy fuels, particularly hydrazine. One solution may be to install operable shutters that can cover over the windows of a habitat when a descent stage is landing at the landing zone or when there is a dust storm on Mars. One of the most challenging questions for window is how to repair or replace a damaged pressure window on the planetary surface. Prof. Larry Bell of the University of Houston has investigated this problem.

\section{FINISHES}

In CSI Division 9, finishes apply to the internal finishes of the living environment, and traditionally cover such staples as paint, tile, carpet, acoustical absorption and plaster. The purposes that these finishes serve on Earth remain largely the same in a Space Habitat, except that the environmental health aspects that are often just footnotes on Earth loom large in an envelope with a mostly or all closed life support system.

FIRE RESISTANCE - The purpose of plaster or gypsum board is to provide fire-rated protections to the secondary structure and separations between occupancies. Although the separation of different tenant occupancies does not arise (yet) in a space habitat, the issue of noncombustible materials looms just as large as it did after the Apollo 1 fire in 1967 that killed three astronauts. Plaster and gypsum are not appropriate materials because of their weight and brittleness, but partitions between com- partments and other panels or surfaces should consist of highly fire-resistant materials. ASTM E-84 defines three combustible properties of materials: flame spread, fuel contributed, and smoke produced. Materials for use in space habitats must score as close as possible to zero on all three scales. Although finish materials are the most frequent culprit in producing toxic smoke, other materials such as the insulation on wires and rubber seals on mechanical equipment can also burn to emit fumes. They must also meet stringent fire resistance criteria.

TOXIC OUTGASSING - The challenge facing most other finishes is the toxic outgassing of solvents and other chemicals. This problem applies to paints, carpeting, and "wall fabrics" alike. To a limited extent, it is possible to "bake" the toxic fumes out of these materials, but in most cases, they outgas over time. There is a very limited number of pigmented paints certified for use in space; such certification is very expensive and applies only to the exact formulation submitted to testing. These constraints make it particularly difficult to design home-like or other comfortable qualities into a space habitat.

FIBERS AND PARTICULATES - Another issue associated with acoustical insulation, fabrics and carpeting is that as they wear and degrade, they release fibers into the atmosphere. Although these fibers generally pose no direct problem to humans, they can pose a problem to the life support system filters where they collect. The crew must clean these filters to prevent them from clogging. Removing and disposing of large quantities of lint is a demand upon the space habitat system and the crew that it would be preferable to avoid.

\section{SPECIALTIES}

This CSI Division covers a melange of products with fairly specialized applications. A space habitat involves potentially a number of these applications, including lockers and stowage compartments, fire extinguishers (handheld), demountable and operable partitions, and toilet, shower and bath accessories. The design of each of these items for space habitats requires careful ergonomic and human factors study. An essential source of information is the Man Systems Integration Standard, NASA STD-3000. One interesting specialty is "exterior sun control devices." It is conceivable that some extravehicular activities on the lunar or Mars surface would benefit from a sun shade that reduced glare and solar heat gain on the space suit.

\section{EQUIPMENT}

This Division encompasses a wide range of products, many of which have analogs or direct equivalents in a space habitat. These products included all the standard household appliances such as clothes washer and dryer, dishwashers, stoves, ovens, refrigerators, and freezers. More exotic but still relevant equipment includes "window washing and building facade maintenance;" audio-visual 
equipment and projection screens; loading dock equipment; waste compactors, destructors and incinerators; athletic, recreational and therapeutic equipment; and medical and hospital equipment. The design of each of these items a space habitat must take into account the gravity and atmosphere regimes. The challenge of designing and building a zero-G clothes washer and dryer for the Space Station led to a decision to simply do the laundry on Earth and provide a sufficient supply of clean clothes to last the crew through a 120 day tour of duty. However, it is unlikely that the crew will bring a 1000 day supply of clean clothes with them to Mars. Therefore, a number of these types of equipment that were avoidable for the Space Station or for a lunar base will become essential for a human Mars mission. Providing a well-prepared gourmet meal on day 701 of the Mars mission will go a lot further to bolster crew moral than an extra megabyte of RAM in an on-board computer. Yet, these types of equipment bring with them increased demands for power, cooling, and waste heat removal, as well as handling large quantities of "gray" wash water. Enhancing these capabilities will translate directly into increased demands upon many other portions of the habitat system.

\section{FURNISHINGS}

Furnishings is probably the most self-explanatory of all the CSI Divisions. The crew will need beds in which to sleep, desks or consoles at which to work and dining areas in which to eat. The Man System Integration Standard, NASA STD-3000 (1995, revision B) provides an excellent point of departure from which to begin designing such accommodations.

\section{SPECIAL CONSTRUCTION: INFLATABLES, DEPLOYABLES, EXPANDABLES}

In the CSI Division, the concept of "special construction" encompasses a wide range of products. In one sense, the entire Space Habitat qualifies as "special construction" if only because it fits the definition of a "precision controlled environment." Yet, in a larger sense, the Space Habitat is simply an extension of Earth architecture that uses various forms of special construction. For a lunar or planetary habitat, these forms of special construction potentially include integrated ceilings, interior framing (secondary structure) systems, athletic rooms, sound and vibration control, radiation protection, dome and inflatable structures, and solar energy systems. Each of these items is easily the topic of another paper, but a few points will explain their relevance.

INTEGRATED CEILINGS - With the many utilities that must connect the various parts of the Space Habitat, it is essential to have a far-reaching and consistent strategy for where those utilities become available to the crew and how the crew can access them for repair. The Integrated Ceiling system offers an opportunity to do both in a sim- ple manner, provided the interior secondary structure accommodates them.

ATHLETIC ROOM - It is a given the crew needs exercise and exercise equipment upon which to do their exercise. However, it remains unsettled whether there should be a dedicated gymnasium, or the crew members watch each other do sit-ups from the breakfast table. Providing a dedicated space to an activity elevates its importance and role both functionally and symbolically.

SOUND AND VIBRATION CONTROL - Within the Space Habitat, there will be many items of equipment involving motors and pumps, especially within the life support system, all of them whirring and humming throughout the day and night. All this activity can translate easily into structure-borne or duct-borne noise unless there is a conscientious effort to eliminate it. The conventional wisdom states that the best approach is point of source isolation, and this is fine insofar as it goes. However, what would be much more effective would be for the secondary structural system to incorporate its own isolation and damping system, tuned to its own natural frequencies. That way, any errant or escaped vibration from equipment will not translate into a larger resonance within the secondary structure.

RADIATION PROTECTION - Radiation is the potential "show stopper" that the space program must confront and address to make a human mission to Mars feasible. What makes it a show stopper is the enormous mass of shielding required to protect the crew both in interplanetary space and on the lunar or Mars surface. The requirement is particularly acute in interplanetary space. The author calculated previously the requirement for 42 to 46 metric tons of water shielding to protect a crew with about 30 $\mathrm{gm} / \mathrm{cm}^{2}$ on the way to Mars in an interplanetary habitat (Cohen, 1996; SAE 961466, Cohen, 1997, SAE 972485). On the Mars surface, this requirement diminishes somewhat because of the planet's mass providing a large measure of partial shielding, and the Mars atmosphere providing about 16 to $22 \mathrm{gm} / \mathrm{cm}^{2}$ at zero altitude (Simonson, 1997, p. 59). However, the moon is a more severe radiation environment, closer to the sun and without an atmosphere to afford such a degree of shielding. On both the Moon and Mars surface it is possible to use the regolith to pile up shielding on the habitats. There are, however practical considerations in how to package this material, the most pedestrian approach being sandbags. Khalili's or MacKenzie's approach of using brick masonry for radiation shielding also show promise.

DOMES AND INFLATABLES - Domes and Inflatables offer the potential for utility structures that are not part of the Life-critical habitat core (for a discussion of criticality, please see Cohen, 1996, AAS 950491, in Stoker \& Emmart, eds). One of the most often suggested uses for inflatables on the moon or Mars is to provide a "greenhouse" in which to grow plants. The inflatable can certainly hold the atmosphere, but it is unlikely that it will 
transmit much or any sunlight that would help the plants to grow. Instead, the lunar or Mars base farm will need a system of artificial lighting. These lights will require a great deal of electrical power, and the most challenging engineering problem is how to reject the waste heat from the lights so as not to cook the plants in the ground. One system that David Bubenheim has pioneered at NASAAmes Research Center involves liquid-cooled lights (Straight, Bubenheim, Kohut, Bates, and Flynn, 1994).

\section{CONVEYING SYSTEMS, ROBOTIC TRANSPORT, ASSEMBLY AND CONSTRUCTION}

This CSI Division generally deals with elevators, escalators, dumbwaiters and the like. However for a lunar or Mars base, the primary conveying systems are likely to involve robotic transport, asembly and construction systems, as well as piloted rovers, both pressurized and unpressurized.

One prime exemplar for an integrated conveying and storage system are geological samples. The crew will gather vast quantities of samples on field explorations, and bring them back to the base for study. It will be necessary to classify, package, label, store and retrieve these samples. This collection will soon grow so large that it will not be feasible to store them inside the pressurized habitat. Also, there is a serious scientific question of whether it is desirable to expose these samples to an atmosphere that contains earthly micro-organisms that could confuse search for life studies. It is likely that at least some samples must remain in the lunar vacuum or Mars atmosphere throughout the period of analysis, or at least until the analysis is complete. These requirements suggest a sample stowage, conveying, and handling system that will allow crew members to order a robot to retrieve a sample from an exterior stowage system, place it in a sample airlock, and then bring it into an atmosphericly isolated glove box where the crew can manipulate it. The crew members will operate analytical tools and instruments in the glove box to conduct the analysis. Once they have satisfied the quarantine requirements for the initial investigation of a sample, it will be possible for them to bring the sample into the ambient cabin atmosphere for further study. The automated conveying, airlock, and glove box system must accommodate this set of operational requirements.

\section{MECHANICAL SYSTEMS}

Mechanical systems include, life support, plumbing, hygiene, heating, ventilating, air conditioning, food growth chambers and fire protection. More than any other single element the life support system and controlled atmosphere is what distinguishes a space habitat from a terrestrial habitat. The life support system is almost certainly the single subsystem with the greatest mass after primary structure. It is also the one system upon which it is most difficult to reduce the mass (except by running open loop and eliminating recycling processors, which is not acceptable for Mars missions). The most optimistic mass reduction projection for life support appears in Drake, (June 1998, p. 32), predicting a possible reduction from $6000 \mathrm{~kg}$ to $4661 \mathrm{~kg}$, compared to a reduction from $10,000 \mathrm{~kg}$ to $5500 \mathrm{~kg}$ for the complete structural system in shifting from a hard pressure vessel to the inflatable "TransHab."

VOLUMETRIC PACKAGING - The life support system is ubiquitous because it is probably the only system that occupies substantial volumes of both equipment rack space and utility chase or plenum space. The convention for Space Station has been to package the life support systems into the standard Space Station Racks, which has resulted in a less than optimal packaging scheme. For lunar and planetary missions, it may be preferable to develop a more flexible packaging scheme that will accommodate more readily the optimal and unique dimensions and characteristics of the life support system.

ADJACENCY AND SEPARATION - The various mechanical systems employ most of the pumps and motors in the habitat that will be a constant source of noise. Barbara Woolford recommends designing the floor plan to place such noise sources -- including the waste management/hygiene facilities -- as far away from the private sleep quarters as possible. Woolford also recommends separating the waste management and personal hygiene system from the food preparation and dining areas for both hygienic and aesthetic reasons (Woolford, Connolly, and Campbell, 1997, p. 264).

ACCESS VERSUS ISOLATION - Because the crew will need to depend upon their own abilities to repair and adjust the subsystems in the interplanetary and planetary habitats. It will be essential to afford easy access to all the potential trouble spots, including leak points, motors, valves, controllers, etc. This requirement poses an implicit contradiction between the need to acoustically isolate these components while providing ready access to them.

\section{ELECTRICAL AND DATA SYSTEMS}

Electrical and data systems are the ubiquitous and allpervasive energy and nervous system of the Space Habitat. There is nary a piece of equipment untouched by some kind of electrical connection, if only to collect data on system status and condition for real time automated diagnostics.

COMPONENTS AND THEIR LOCATIONS - The size of the electrical components ranges from high voltage and high amperage breaker panels and transformers for power conditioning and distribution down to delicate microelectronics. With this diversity of components, several integration challenges emerge. First is to separate major power conditioning and distribution equipment from the main living areas. Under the conventional building electrical codes, switch panels require unobstructed 
access, often within a secure closet, and transformers stand outside the building for fire protection. The decision about whether to "cold plate" the power conditioning equipment and to place it outside the pressurized environment or to place it in an isolated volume within the pressurized environment has far-reaching implications for safety and operations. On Space Station, the decision was to place the power conditioning equipment outside the habitable modules. Any future repairs to these systems will be possible only by astronaut EVA.

RFI AND EMI - Perhaps the thorniest integration problem is avoidance of radio frequency interference (RFI) and electrical magnetic field interference (EMI). The RFI may originate from a variety of mechanical and computer sources, and may interfere with communications and computation equipment. It is possible to shield against RFI to some extent with metallized membranes or foils. EMI usually tends to originate from the power distribution system in which large currents generate electrical and magnetic fields that can wreak havoc with microcircuitry, from cathode ray tubes, or from other devices with large electromagnets. The main protection from EMI is physical separation of power cables from computer systems and data cables. For example, in one wind tunnel control room project at Ames Research Center, the author worked with a system that required $.5 \mathrm{~m}$ separation between $480 \mathrm{~V}$ power control cables and the computers. The layout of raceways and utility chases for power and data cables must take these separation requirements into account.

\section{CONCLUSION}

This essay presents a summary of the design integration issues for key materials, structures, components and subsystems within a space habitat for a lunar, planetary or interplanetary mission. It shows that the Construction Specifications Institute's Sixteen Division Index is an appropriate "work breakdown structure" for space architecture in general and for habitats in particular. With a comprehensive view of this index, it is possible to develop a design integration strategy that anticipates and avoids conflicts between systems and components. Although this paper accepts the baseline assumptions of the NASA Mars Design Reference Mission, it is independent of any specific habitat design. It looks forward toward the evolution and maturation of planetary habitat design to include assemblable, deployable and in situ construction techniques.

\section{ACKNOWLEDGEMENTS}

I wish to thank David Bubenheim, NASA-Ames Research Center, Kriss Kennedy, NASA-Johnson Space Center, Bruce MacKenzie, Draper Laboratory, and Madhu Thangavelu, University of Southern California, for their generous assistance in helping me to research and prepare this paper.

\section{BIBLIOGRAPHY}

1. Abarbanel, Jenine E., Bateman, Ted A., Criswell, Marvin E., \& Sadeh, Willy Z., (1996) A Framing System for a Lunar/Martian Inflatable Structure, in Johnson, Stewart W., ed., pp. 1069-1075.

2. Cohen, Marc M. , (1986) Lightweight Structures in Space Station Configurations, in Sedlak, Vincenz, ed., First International Conference on Lightweight Structures in Architecture, Sydney, Australia: University of New South Wales/ Unisearch Limited.

3. Cohen, Marc M., and Bussolari, Steven, (1987, April) Human Factors in Space Station Architecture II -- EVA Access Facility: A comparative analysis of four concepts for on-orbit space suit servicing, NASA TM 86856, Washington DC: NASA Scientific and Technical Information Branch.

4. Cohen, Marc M., (1995, April) The Suitport's Progress, AIAA-95-1062, Life Sciences and Space Medicine Conference, April 3-5, 1995, Houston, TX., Reston VA: American Institute of Aeronautics and Astronautics.

5. Cohen, Marc M., (1996) First Mars Outpost Habitation Strategy, AAS 95-491, in Stoker, Carol R. \& Emmart, Carter, eds, Strategies for Mars: A Guide to Human Exploration, San Diego, CA: American Astronautical Society/ Univelt Inc., pp. 465-512.

6. Cohen, Marc M., (1996) Design of a Planetary Habitat Versus an Interplanetary Habitat, SAE 961466, 26th International Conference on Environmental Systems, Monterey, CA, July 8-11, 1996, Warrendale, PA: Society of Automotive Engineers.

7. Cohen, Marc M., (1997) Design Research Issues for an Interplanetary Habitat, SAE 972485, 27th International Conference on Environmental Systems, Lake Tahoe, NV, July 14-17, 1997, Warrendale, PA: Society of Automotive Engineers..

8. Cohen, Marc M., \& Kennedy, Kriss J., (1997) Habitats and Surface Construction Technology and Development Roadmap, NASA CP-97-206241, in Noor, Ahmed K. \& Malone, John B., eds., Government-Sponsored Programs on Structures Technology, Hampton, VA: Langley Research Center, pp. 75-96.

9. Drake, Brett G., (1998, June) Reference Mission Version 3.0 Addendum to the Human Exploration of Mars: The Reference Mission of the NASA Mars Exploration Study Team, JSC EX13-98-06, Houston TX: Johnson Space Center, Exploration Office, Advanced Development Office.

10. Hoffman, Stephen J. \& Kaplan, David I., eds, (1997, July) Human Exploration of Mars: The Reference Mission of the NASA Exploration Study Team, NASA SP 6107, Houston, TX: Johnson Space Center.

11. Johnson, Stewart W. ed, Space V: Engineering, Construction and Operations in Space, Proceedings of the Fifth International Conference on Space '96, June 1-6, 1996, Albuquerque NM, New York: American Society of Civil Engineers.

12. Khalili. N.E.(1985) Magma, Ceramic and Fused Adobe Structures Generated In-Situ, Lunar Bases and Space Activities of the 21st Century, in Wendell.W. Mendell, ed, Houston: Lunar and Planetary Institute.

13. Khalili. Nadar .E. (1986)Ceramic Houses and Earth Architecture, San Francisco: Harper and Row.

14. Khalili. N.E. (1990) Lunar, Martian and Asteroid Structures Built In-Situ. Space '90 Proceedings of Space '90, New York, NY: American Society of Civil Engineers.

15. Khalili. N.E. (1989, July) Lunar Structures Generated and Shielded With On-Site Material, Journal of Aerospace Engineering, Vol.2. No.3.

16. Lin, T. D., Tseng, Liang, and Chou, Sam, (1984) Lunar Concrete Made with the Dry-Mix/Steam Injection Method, in Johnson, Stewart W., ed., pp. 592-599. 
17. Mackenzie, Bruce (1988) Building Mars Habitats Using Local Materials, Case for Mars III conference proceedings, AAS 87-216, vol 74, page 575 .

18. Mackenzie, Bruce, (1988, August) Homesteading Mars, Engineering, Construction, and Operations in Space, Proceedings of Space 88, New York, NY: American Society of Civil Engineers, pages 465-479.

19. MacKenzie, Bruce, (1998, May) Homesteading Mars / The Vaults of Mars, International Space Development Conference of the National Space Society, Milwaukee WI.

20. Man-System Integration Standard, (1994, August) NASA Standard 3000, Houston, TX: Johnson Space Center, Code SP2.

21. McKay, David S., and Allen, Carlton C. (1996) Concrete -A Practical Construction Material for Mars, in Johnson, Stewart W. ed, pp. 566-570.

22. Simonson, Lisa, (1997) Analysis of Lunar and Mars Habitation Modules for the Space Exploration Initiative (SEI), in Wilson, Miller, Konradi, and Cucinotta, eds, pp. 43-77.

23. Straight, C., Bubenheim, D.L., Kohut, L., Bates, M., and Flynn, M.(1994) Energy Utiliazation Concepts for the CELSS Antarctic Analog Project, SAE 941353, 24th International Conference on Environmental Systems, Warrendale, PA: Society of Automotive Engineers.

24. Vaicaitis, Rimas, (1985) Vibrations and Structureborne Noise in Space Station, NASA CR-176291.

25. Wilson, J. W., Miller, J., Konradi, A., and Cucinotta, F. A.,
(1997, December) Shielding Strategies for Human Exploration, NASA CP 3360, Proceedings of a workshop at Johnson Space Center, Houston, TX, December 6-8, 1995, Hampton, VA: Langley Research Center.

26. Woolford, Barbara, Connolly, John H., and Campbell, Paul, (1997) Human Factors Implications for Shielding, in Wilson, Miller, Konradi, and Cucinotta, eds, pp. 261-269.

27. Vaicaitis, Rimas, (1985, June) Vibrations and Structureborne Noise in Space Station, NASA CR-176291.

\section{CONTACT}

Please send comments or inquiries to:

Marc M. Cohen, Arch.D,

Archtitect

Advanced Projects Branch

Space Projects Division

Mail Stop 244-14

NASA-Ames Research Center

Moffett Field, CA 94035-1000

TEL +1 (650) 604-0068

FAX +1 (650) 604-0673

e-mail mcohen@mail.arc.nasa.gov 


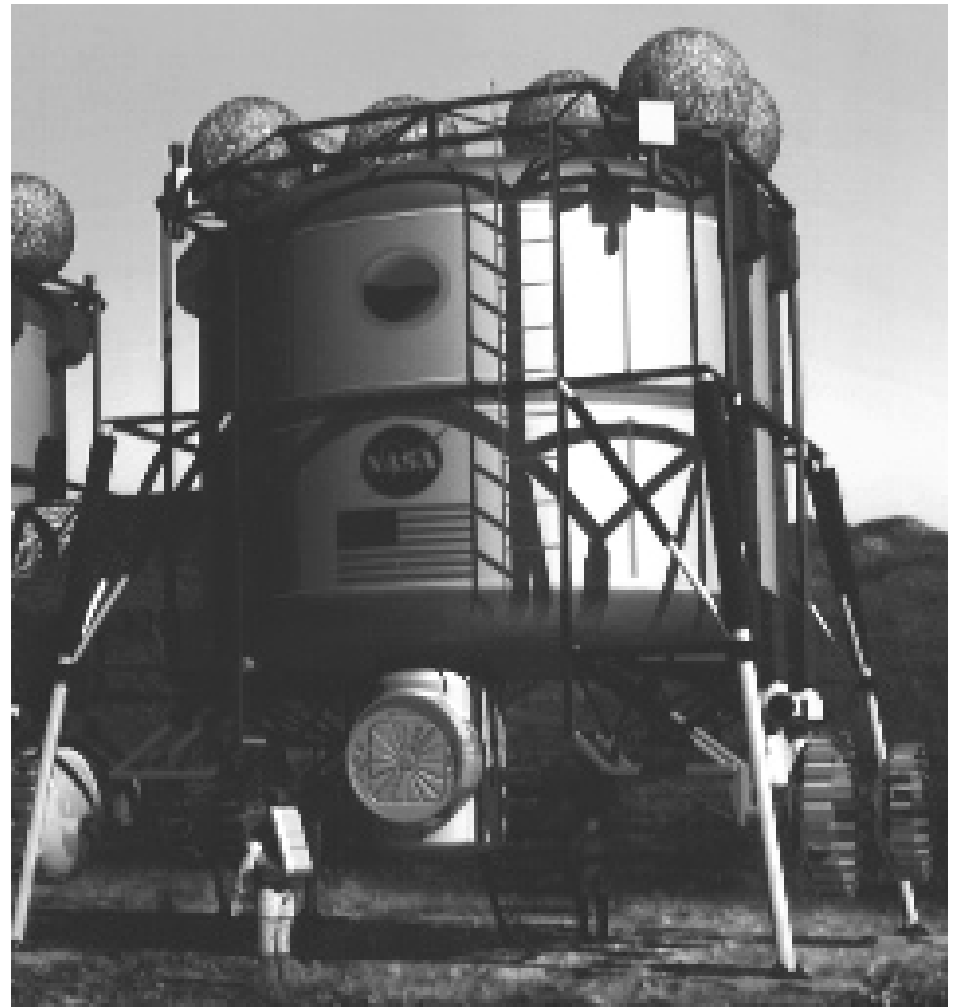

Figure 1. Pre-integrated, hard pressure vessel habitat. Concept by Kent Joosten at Johnson Space Center, courtesy of Kriss Kennedy, NASA Johnson Space Center

Figure 2. Class 2 Prefabricated deployable / inflatable habitat, courtesy of Kriss Kennedy, NASA Johnson Space Center
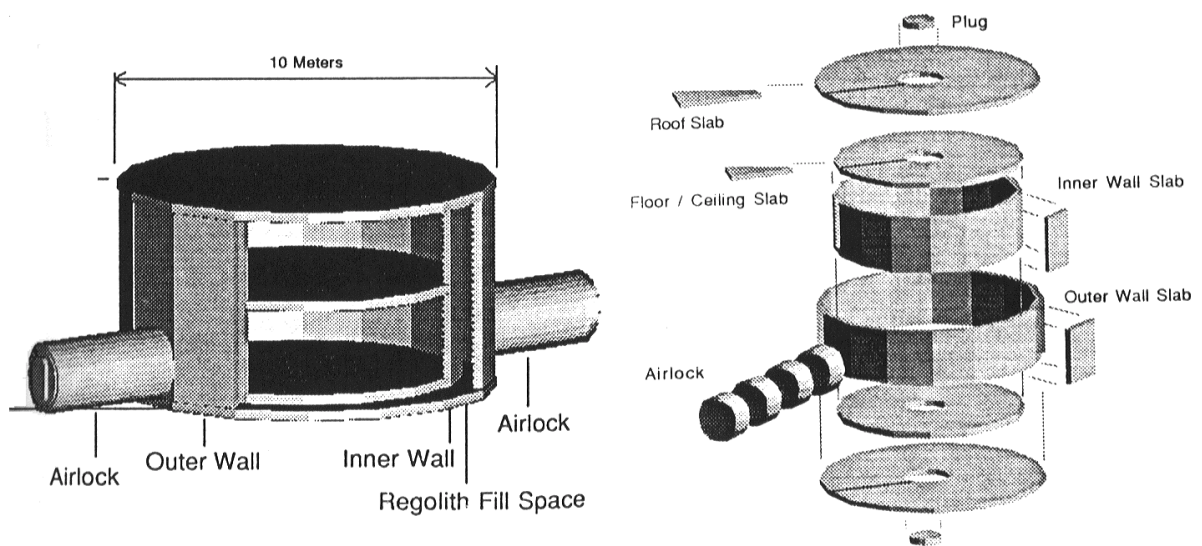

Figure 3. Class 3 In Situ constructed concrete habitat, courtesy of Kriss Kennedy, NASA Johnson Space Center 


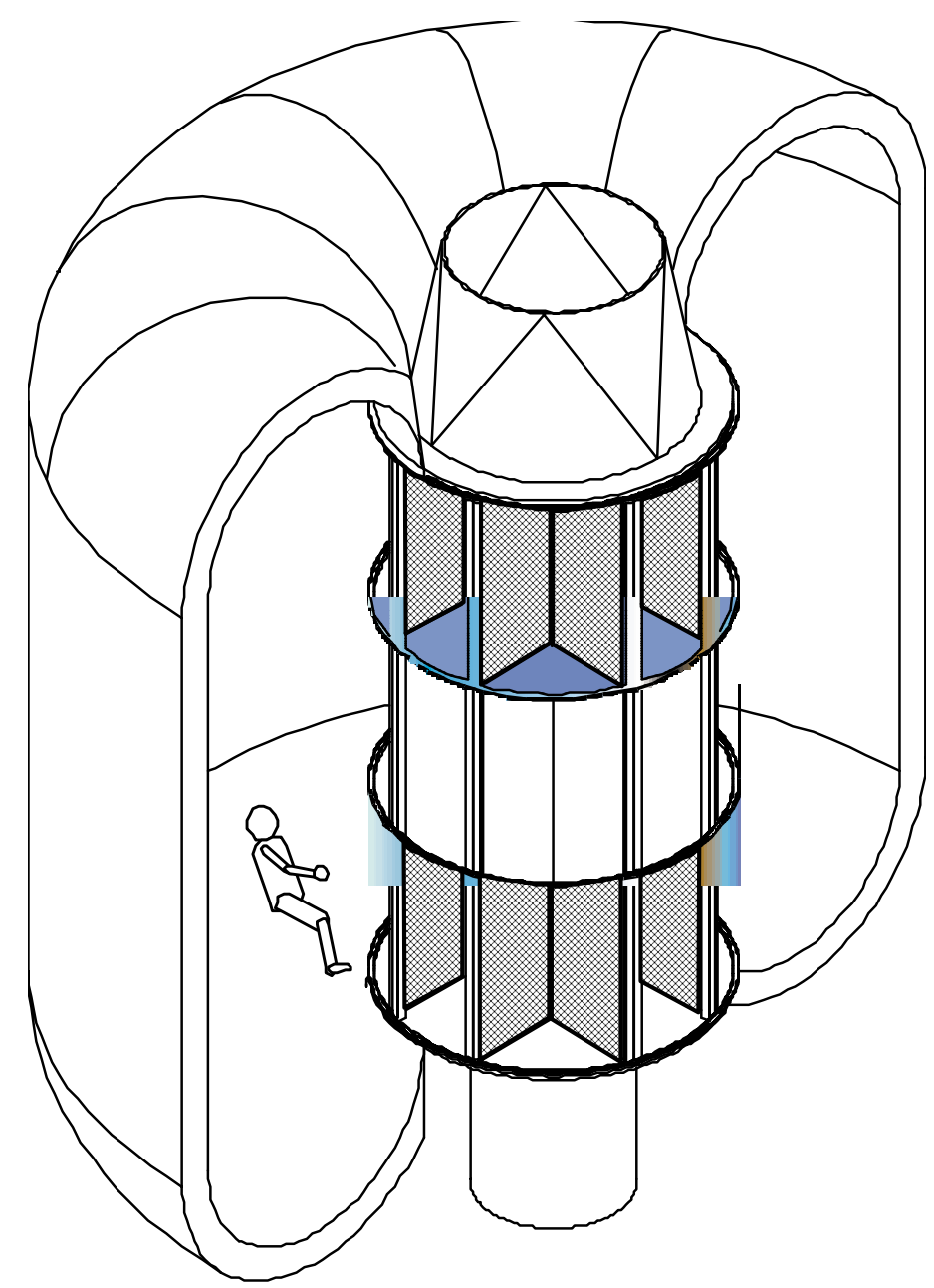

Figure 4. Cross Section through Kriss Kennedy's TransHab inflatable module concept, revealing the Central Core, courtesy of Kriss Kennedy, NASA Johnson Space Center 